Part One

Fundamental

Background 


\title{
Overview of Composite Materials and their Automotive Applications
}

\author{
Ali Hallal ${ }^{1}$, Ahmed Elmarakbi ${ }^{2}$, Ali Shaito ${ }^{1}$ and Hicham El-Hage ${ }^{1}$ \\ ${ }^{1}$ Department of Mechanical Engineering, LIU, Beirut, Lebanon \\ ${ }^{2}$ Department of Computing, Engineering and Technology, University of Sunderland, \\ Sunderland, SR6 ODD, UK
}

\subsection{Introduction}

This chapter presents an overview of recent automotive applications of advanced composites. A summary of available composites that could be used in automotive industries is presented. This work mainly deals with new research and studies done in order to investigate the present and potential use of composites for automotive structural components (e.g. tubes, plates, driveshafts, springs, brake discs, etc.). The important conclusions of these experimental and numerical simulation studies are shown in detail. It is important to note that most studies have an interest in enhancing the mechanical properties of automotive parts as well as providing better ecological and economical solutions. The influence of reinforcement types and architecture on the mechanical behaviour of automotive parts is investigated.

It is remarked that unidirectional composites and composite laminates are the most used composites, with a domination of glass fibres. However, carbon reinforced polymers and carbon ceramic composites along with nanocomposites could be considered as the most advanced composites currently in use for the automotive industry. Moreover, the emergence of natural fibre reinforced polymers, green composites, as a replacement of glass fibre reinforced polymers is discussed.

Recently, the use of composite materials has increased rapidly in automotive domains. As reported, according to [1], it is remarked that the total global consumption of lightweight materials used in transportation equipment will increase at a compound annual growth rate (CAGR) of 9.9\% in tonnage terms and 5.7\% in value terms between 2006 and 2011 (from

Advanced Composite Materials for Automotive Applications: Structural Integrity and Crashworthiness,

First Edition. Edited by Ahmed Elmarakbi.

(C) 2014 John Wiley \& Sons, Ltd. Published 2014 by John Wiley \& Sons, Ltd. 
42.8 million tons/US $\$ 80.5$ billion in 2006 to 68.5 million tons/US\$106.4 billion in 2011) [2]. The use of composites consists of chassis parts, bumpers, driveshafts, brake discs, springs, fuel tanks, and so on.

From a historical point of view, it should be noticed that the first car body made from (glass fibre reinforced polymer, GFRP) composites was for the Chevrolet Corvette, which was introduced to the public at Motorama show at New York in 1953 [3]. For these days, the Corvette series still use composite materials in its design. In motor sports, the use of carbon fibre reinforced polymers has been shown in Formula 1, with the McLaren MP4 in 1981. The open wheel car benefits from lighter body, which leads to a well distributed weight in order to achieve more mechanical grip on the track which significantly increases the overall performance of the car. Nowadays, all Formula series cars and other racing touring cars use composites in huge amounts in almost all of their body parts.

Composites have many advantages over traditional materials, such as their relatively high strength and low weight, excellent corrosion resistance, thermal properties and dimensional stability and more resistance to impact, fatigue and other static and dynamic loads that car structures could be subjected. These advantages increase the performance of cars and lead to safer and lower energy consumption. It should be noticed that car performance is affected not only by the engine horsepower, but also by other important parameters such as the weight/horsepower ratio and the good distribution of the weight. Moreover, lighter vehicles lead to a reduction of fuel consumption. It has been estimated that the fuel economy improves by $7 \%$ for every $10 \%$ of weight reduction from a vehicle's total weight $[1,2]$. It is reported that using carbon fibre composites instead of traditional materials in body and chassis car parts could save $50 \%$ of weight $[1,2]$. In addition, it means for every kilogram of weight reduced in a vehicle, there is about $20 \mathrm{~kg}$ of carbon dioxide reduction [2].

The major problems still facing the large use of composites in automotive domains are: the high cost in comparison with traditional materials (steel, alloy, aluminium), the complex and expensive manufacturing process for a large number of parts, the unknown physical (mechanical, thermal) behaviour of some kind of composites. Thus, many studies and research are conducted to solve these problems in order to extend the use of composites in large mass. Ford, with a collaboration with materials experts through the Hightech NRW research project, leads the search for a solution of a cost efficient manufacturing of carbon fibre composite components [4]. As estimated by Ford, the use of carbon fibre composites in addition to other advanced materials in the manufacturing of many automotive parts will reduce the weight of their cars by $340 \mathrm{~kg}$ at the end of the decade [4]. Another example is the consortium, led by Umeco and partnered by Aston Martin Lagonda, Delta Motorsport Ltd, ABB Robotics and Pentangle Engineering Services Ltd, that has been created to look into the potential for using high-performance composites. The project aims to reduce the cost of composite body in white vehicle structures for the mainstream automotive sector [5].

Many types of composites exist, which give the opportunity to select the optimum material design for any structure. However, this leads to many studies that deal with the mechanical behaviour of composites. The most used composites are composite laminates which consist of several plies with unidirectional long fibres. More developed kinds of composites known as textile composites (woven, braided and knitted fabrics) has emerged recently to be adopted in automotive applications. Moreover, nanocomposites have been used in order to enhance the performance of car structures. Hybrid composites also have been adopted especially in 
designing tubes and beams. Hybrids consist of several layers of composites and other types of materials, such as aluminium. The aluminium layer is reinforced by laminated or unidirectional (UD) composites composites. These kinds of lightweight materials are used to resist impact loading, as will be shown in the section below.

In this chapter, a brief general introduction of composites type is presented in the second section, while the automotive applications of advanced composites are discussed in the third section. In the fourth section, the potential of analytical and numerical analysis is presented.

\subsection{Polymer Composite Materials}

In general, composite materials are composed from at least two materials, where one is the reinforcing phase and the other is the matrix. Many combinations can be shown, with different kinds of materials and architectures.

There are two classification systems of composite materials. One is based on the matrix material (metal matrix composites, MMC; ceramic matrix composites, CMC; polymer matrix composites, PMC) and the second is based on the material structure: particulate (random orientation of particles; preferred orientation of particles), fibrous (short-fibre reinforced composites; long-fibre reinforced composites) and laminate composites.

The various PMC are classified as thermoplastic and thermosets and can be reinforced with various types of fibres depending upon the applications. The PMC are used in various automotive applications like crashworthiness, body panels, bumpers and so on. The CMC are used in elevated temperatures of various engine components and braking systems. The MMC use magnesium, copper and aluminium as their matrix with fibres to be used in various engine and crash absorbing components. Moreover, MMC with aluminium matrix and ceramic based composites find some automotive applications with supercar brake discs.

The PMC have heavily been used in the automotive industry. Polymers used in automotive applications are divided into thermoplastics and thermosets. Thermoplastics are high molecular weight materials that soften or melt on the application of heat. Thermoset processing requires the non-reversible conversion of a low molecular weight base resin to a polymerised structure. The resultant material cannot be re-melted or re-formed.

In automotive applications, reinforced plastics are the major composite material. For polymer composites, common fillers used include calcium carbonate $\left(\mathrm{CaCO}_{3}\right)$, talc, wollastonite, glass and carbon fibre. Some of the common processing techniques for polymer composites are: injection moulding, sheet moulding compound (SMC), glass-mat thermoplastic (GMT) compression moulding, resin transfer moulding (RTM) and reaction injection moulding (RIM).

Some of the factors affecting the processing and manufacture of polymer composites are fibre distribution in the matrix, compatibility between the matrix and fibres, fibre orientation and thermal stability of the fibre.

A common processing technique for the production of polymer composites is thermoforming. Thermoforming is commonly used to produce fibre-mat thermoplastic composites. The fibre and the polymer are inserted into a heated mould. The thermoplastic then flows into the fibre component. The hybrid material is then combined into a composite in a cold press. Compression moulding using thermoset polymer matrices is another major processing technique used to manufacture large parts for the automotive industry. 
The main categories of polymer composites used in automotive applications are as follows [6]:

- Non-structural composites, composites composed of short glass fibre-reinforced plastics with the reinforcement in the range of $10-50 \%$ by weight used in pedal systems, mirror housing and so on.

- Semi-structural composites, composites composed of several layers of the reinforcement, which is in the form of a mat in a matrix. The mat could be a chopped strand mat, a random continuous strand mat, or a unidirectional mat. The matrix could be a thermoplastic or a thermoset. These composites are used in body panels, front end structures, seat backs and so on.

- Structural composites, structural thermoplastic composites (TPC), structural reaction injection moulded core parts, bumper systems and so on.

\subsubsection{Non-Structural Composites}

The use of composite materials has been limited to automotive structural components, however recently there has been a wide use of composites in non-structural functional components. Schouwenaars et al. [7] studied the fracture during assembly of a radiator head produced from a nylon/33\% short glass fibre composite. The study focused on finding the elastic constants and fracture stresses and on resolving some of the manufacturing problems such as distortion after moulding and deformations induced during assembly. They used a combination of in situ measurements, microscopy and reverse modelling of non-linear material properties to determine the stiffness constants and strength as a function of fibre length distribution and fibre orientation distribution. The integrated approach was used effectively to resolve the manufacturing problems presented.

Lee et al. [8] addressed the advantages of using composites in reducing the mass of automotive components and improving the fuel efficiency by developing a hybrid valve lifter to be used in an automotive internal combustion engine. The lifter was made from carbon fibre/phenolic composite and steel. The design and manufacture of the hybrid valve was investigated based on the functional requirements such as durability. The mass of the composite was $35 \%$ lighter than the conventional steel valve lifter and showed to be durable for the test loads.

Imihezri et al. [9] studied the mould flow and component design of a $30 \%$ glass fibre polyamide composite to be used as a clutch pedal. Different profile cross-sections were analysed using finite element analysis for stress and using mould flow software for flow properties.

\subsubsection{Semi-Structural Composites}

Sheet moulded compound (SMC) panels as exterior body panels have been increasingly used in automotive industry [10]. Among the main factors to consider in the design of the body panels are material cost and mass reduction. Mass reduction is achieved by using materials with the high strength-to-weight ratios which composite materials offer [2]. However, there are some barriers for the use of composites in the production of automotive parts, such their cost and their manufacturing.

General Motors Research Laboratories evaluated different body panel designs for a front wheel drive compact car for equal stiffness requirements [11]. The materials considered as 
a substitute for steel were aluminium, glass SMC and carbon SMC. The SMC fibre content was in the range of $10-70 \%$ by weight. The glass SMC showed $27 \%$ reduction in mass, while aluminium and carbon SMC showed a mass reduction of 35 and $45 \%$, respectively. Although the carbon SMC showed the highest mass reduction, it had a higher cost due to the higher selling price of carbon fibres. General Motors also uses continuous fibre glass epoxy composites for front and rear leaf springs in selected passenger cars and for longitudinal leaf springs in the GM mini-van. The glass/epoxy leaf spring had a mass reduction ratio of 4: 1 over the conventional steel leaf.

Feraboli et al. [12] studied the effect of fibre architecture on the delamination and flexural behaviour of carbon/epoxy body panels of the Lamborghini Murcielogo. They studied the use of four prepreg tapes, two fabrics and woven laminates over directional tape. The strength, durability, environmental resistance, vibration damping and surface finish of the composite body panels were investigated. The body panels were bonded to the tubular steel chassis by a methacrylate adhesive which was found to be effective than other adhesives like epoxy and polyurethane.

Feuillade et al. [13] studied the influence of material formulation and SMC process on the surface quality of SMC body panels. The main parameters considered were the amount of sizing on the fibres, the type of antistatic agent and its deposit method and the type of film former. Two commercially sized glass fibres were studied. The results showed that, during the impregnation process, the natures of the antistatic agent and the film former, the fibre wetting properties and the sizing influenced the surface quality of the SMC moulded panels.

Ning et al. [14] designed, analysed and manufactured an air conditioning cover roof door on a mass transit bus. Thermoplastic composites and thermoforming processing technology was used in the manufacture of the part. The composite was found to have weight savings of 39\%, as compared to aluminium, with an enhanced rigidity of $42 \%$ reduced free-standing deflection.

\subsubsection{Structural Composites}

In addition to the requirements of light weight and lower cost, materials used in automotive applications should also meet the requirements of safety and the ability to absorb impact energy in what is referred to as crashworthiness. Polymer composites have been replacing metal components due to their reduced weight (which improves fuel consumption), their durability and their crashworthiness. Several studies were done on the impact energy absorption, durability and the crushing behaviour of polymer composites [15-24].

Davoodi et al. [25] studied the design of a fibre-reinforced epoxy composite bumper absorber. The study focused on studying the use of composites in energy absorption in a car bumper as a pedestrian energy absorber. A carbon reinforced composite was investigated. It was found that the fibre-reinforced epoxy composite absorber is sufficient for pedestrian impact and can substitute for the existing materials, such as expanded polypropylene foam.

Bisagni et al. [26] studied the progressive crushing behaviour of fibre-reinforced composite energy absorbers for Formula One side impact and steering column impact. Two series of tubes with different lamina were investigated. A finite element model using LS-DYNA was also developed. The composite absorbers had a high capacity of energy absorption. The numerical model accurately predicted the overall shape, magnitude of impact, deformation and failure of the composite absorbers with about $10 \%$ difference to experimental results. 
Launay et al. [27] studied the cyclic behaviour of a 35\% short glass fibre-reinforced polyamide composite to be used in an automotive application. Mechanical tests were done on two different relative humidity specimens. The creep and stress relaxation behaviour of the materials were studied to predict the fatigue life of the polymer matrix composite under different loadings and environmental conditions.

Ruggles et al. [28] studied the fatigue properties of carbon fibre-reinforced epoxy matrix composites. The study focused on developing experimentally based, durability-driven design guidelines for the long-term reliability of carbon reinforced composites for structural automotive components. A temperature-dependence study was also done to study the variation of the fatigue behaviour of the composite with temperature.

It is worth mentioning that composites used in automotive applications are joined in different methods. The main methods are mechanical fastening, adhesive bonding and welding. Mechanical joints such as rivets and bolts have the disadvantage of creating stress concentrations. Adhesive bonding uses a combination of polymer-based adhesive blends and provides some advantages, such as controlled mechanical properties of the adhesive, smooth surface finish between the joined materials, increased life time of the joint and good sealing. Welding, which is commonly used in metallic parts, has limited applications with composites. Welding has some advantages, such as durability and short processing time. For thermoplastic composites, the common welding techniques are: ultrasonic, induction and resistance welding.

Concerning advanced composites used or to be implemented in automotive industries, fibre reinforced polymers (FRP) with glass, aramid, carbon and graphite fibres should receive notice (Table 1.1). The polymeric matrix is in a general epoxy resin or polyester (Table 1.2). However, more recently nanocomposites have found some applications in automotive industries. Moreover, metal matrix composites (MMC) with aluminium matrix and ceramic based composites found some automotive applications with supercar brake discs. Composite architectures found in automotive applications are composite laminates, textiles, hybrids and nanocomposites. Tables 1.1, 1.2 and 1.3 show the mechanical properties of some fibre/polymeric matrices and composites. It is well remarked the advantage that composites bring in terms of high stiffness with a low density material.

Advanced composite materials with long fibres can be categorised into three major categories: laminates, hybrid composites and textiles.

Table 1.1 Mechanical properties of some fibres and metals [29].

\begin{tabular}{lcccccc}
\hline Material & $\begin{array}{c}\text { Young's } \\
\text { modulus } \\
\text { (Gpa) }\end{array}$ & $\begin{array}{c}\text { Shear } \\
\text { modulus } \\
(\mathrm{Gpa})\end{array}$ & $\begin{array}{c}\text { Axial } \\
\text { Poisson's } \\
\text { ratio }\end{array}$ & $\begin{array}{c}\text { Ultimate } \\
\text { strength } \\
(\mathrm{Mpa}) \text { tension }\end{array}$ & $\begin{array}{c}\text { Strain to } \\
\text { failure } \\
(\%)\end{array}$ & $\begin{array}{c}\text { Density } \\
\left(\mathrm{Kg} / \mathrm{m}^{3}\right)\end{array}$ \\
\hline Carbon fibre HT-T300 & 230 & 23 & 0.23 & 3530 & 1.5 & 1750 \\
Carbon fibre IM-T800 & 294 & 23 & 0.23 & 5586 & 1.9 & 1800 \\
Carbon fibre HM & 385 & 20 & 0.23 & 3630 & 0.4 & 2170 \\
E-glass fibre glass & 72 & 27.7 & 0.3 & 3450 & 4.7 & 2580 \\
S-glass fibre & 87 & 33.5 & 0.3 & 4710 & 5.6 & 2460 \\
Kevlar 49 fibre & 124 & 5 & 0.3 & 3850 & 2.8 & 1440 \\
Steel & 206 & 81 & 0.27 & 648 & 4 & 7800 \\
Aluminium & 69 & 25.6 & 0.35 & 234 & 3.5 & 2600 \\
\hline
\end{tabular}


Table 1.2 Mechanical properties of some polymeric matrices [29,30].

\begin{tabular}{lcccccc}
\hline Material & $\begin{array}{c}\text { Young's } \\
\text { modulus } \\
\text { (Gpa) }\end{array}$ & $\begin{array}{c}\text { Shear } \\
\text { modulus } \\
\text { (Gpa) }\end{array}$ & $\begin{array}{c}\text { Axial } \\
\text { Poisson's } \\
\text { ratio }\end{array}$ & $\begin{array}{c}\text { Ultimate } \\
\text { strength } \\
\text { (Mpa) tension }\end{array}$ & $\begin{array}{c}\text { Strain to } \\
\text { failure }(\%)\end{array}$ & $\begin{array}{c}\text { Density } \\
\left(\mathrm{Kg} / \mathrm{m}^{3}\right)\end{array}$ \\
\hline Epoxy & 3.1 & 1.2 & 0.3 & 70 & 4.0 & 1200 \\
Polyester & 3.5 & 1.4 & 0.3 & 70 & 5.0 & 1100 \\
Resin RTM 6 & 2.89 & 1.08 & 0.34 & 75 & 3.4 & 1140 \\
Resin RTM 120 & 2.60 & 0.96 & 0.35 & 77 & - & 1200 \\
\hline
\end{tabular}

\subsubsection{Laminated Composites}

Composite laminates, also known as laminated composites, are composed from different plies, where each ply is considered as a UD long fibre lamina. The mechanical behaviour of each lamina is considered to be transverse isotropic, while the behaviour of the laminated composite is orthotropic. This category represents the most used kind of composites. Several kinds of architecture could be found, such as the cross-ply $[0,90]$ (Figure 1.1), the bi-directional $[-\theta$, $+\theta]([-45,+45],[-30,+30])$, in addition to the tri-axial laminates $[-\theta, 0,+\theta]$. Laminated composites provide good in-plane mechanical properties: high in plane Young's moduli, shear modulus and in-plane ultimate strength. However, they lack stiffness in the out of plane direction, known as the through thickness direction or $Z$ direction. This implies adding more layers in order to strengthen the through thickness direction, which means more weight and cost and prevents the manufacturing of complex shapes. Moreover, composite laminates are prone to delamination and inetrlaminar shear.

\subsubsection{Textile Composites}

More advanced long fibre composites have emerged known as textile composites. Textiles are categorised into three major fabric kinds: woven, braided and knitted fabrics. They are introduced to improve the mechanical behaviour of composites and to offer more choices of composite architectures. Textiles are made from interlaced, interlocked, or knitted yarns that

Table 1.3 Mechanical properties of different kinds of composites.

\begin{tabular}{lccc}
\hline Composite & $\begin{array}{c}\text { Longitudinal } \\
\text { Young's modulus } \\
\text { (Gpa) }\end{array}$ & $\begin{array}{c}\text { Ultimate } \\
\text { strength } \\
(\mathrm{Mpa}) \text { tension }\end{array}$ & $\begin{array}{c}\text { Density } \\
\left(\mathrm{Kg} / \mathrm{m}^{3}\right)\end{array}$ \\
\hline Composite unidirectional graphite/epoxy & 181 & 1500 & 1600 \\
Composite unidirectional glass/epoxy & 38.60 & 1062 & 1800 \\
{$[0,90]$ graphite/epoxy } & 95.98 & 373.0 & 1600 \\
{$[0,90]$ glass/epoxy } & 23.58 & 88.25 & 1800 \\
Textile 2D "Taffetas" carbon/epoxy & 59.4 & 515.05 & 1500 \\
Textile 3D "interlock" & 49.02 & 672 & 1400 \\
Textile 3D "orthogonal" & 57.5 & 770 & 1500 \\
\hline
\end{tabular}




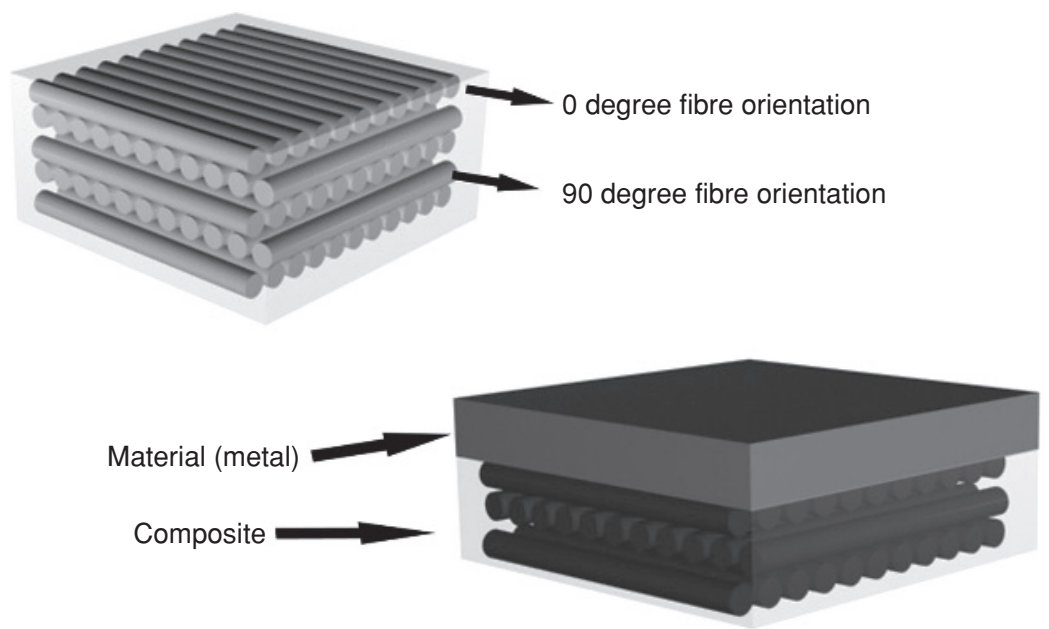

Figure 1.1 Cross-ply laminated composites and hybrid metal-composite material.

undulate above and beneath other yarns to form a complex architecture. Known textiles are composed of yarns with long fibres impregnated in polymer resin, metal, or ceramic matrices. Different 2D and 3D geometries and structures of woven, braided and knitted fabrics could be classified according to the number and shape of yarns. Thus, a large number of different architectures are introduced due to the development and demand needs of industries.

Woven composites represent the biggest category of textiles. Concerning the $2 \mathrm{D}$ woven fabrics, the composite is made of two sets of yarns: the warp and weft yarns. They are interlaced in a $90^{\circ}$ "in-plane". In this kind of woven fabrics, one type of yarn (warp or weft) goes beneath only one set of the other type of yarn and they have a sinusoidal longitudinal profile. The 2D woven composites can be categorised into three major types: the plain weave, the harness satin weave and the twill weave fabrics (Figure 1.2).

The 3D woven composites introduce a yarn in the through thickness direction. The 3D woven composites are designed in order to reinforce the third direction and to avoid delamination between the layers. They are widely used in highly advanced industries, especially in the aeronautics fields, due to their stability and strength in all three axes. The weaver yarns in these composites go beneath more than one set of layers. They are divided into two types: Orthogonal weave and angle interlock weave fabrics. These two types are also divided into two kinds of fabrics: the layer-to-layer and the through-thickness weaves. 3D orthogonal woven composites are characterised by three set of orthogonal yarns: warp weaver yarns, stuffer yarns and weft yarns. However, the angle interlock fabrics can consist of two or three yarn types. In angle interlock fabrics, the warp weaver yarns have a crimp angle between 0 and $90^{\circ}$, while in orthogonal fabrics these yarns have a $90^{\circ}$ angle with the (xy) plane (Figure 1.3).

Concerning the braided fabrics, they have an architecture close to those of 2D woven composites, but in this case the yarns are interlaced by a braider angle which is different from $90^{\circ} .2 \mathrm{D}$ braided composites are divided in general into: diamond fabrics (Figure 1.4a) and tri-axial fabrics (Figure 1.4b). Diamond fabrics consist of only two sets of braider yarns, while tri-axially braided fabrics have an additional axial yarn. The main advantage of these 


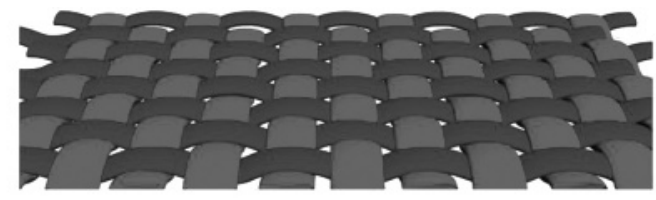

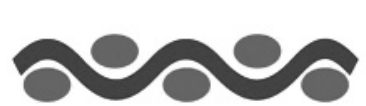

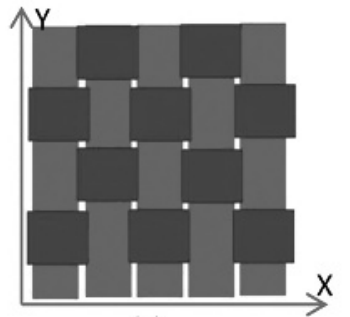

(a)
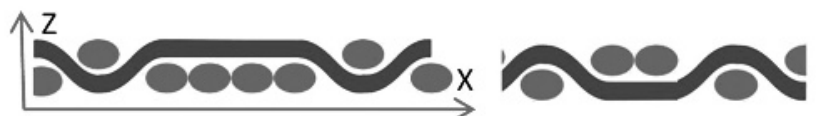

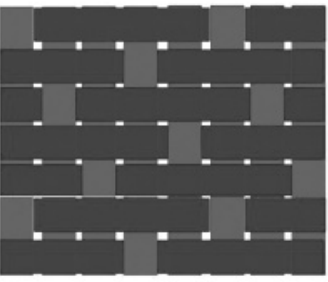

(b)

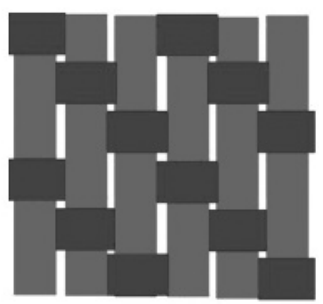

(c)

Figure 1.2 2D woven composites: (a) 2D plain weave composite, (b) Five harness satin weave composite, (c) 2D twill weave composite.
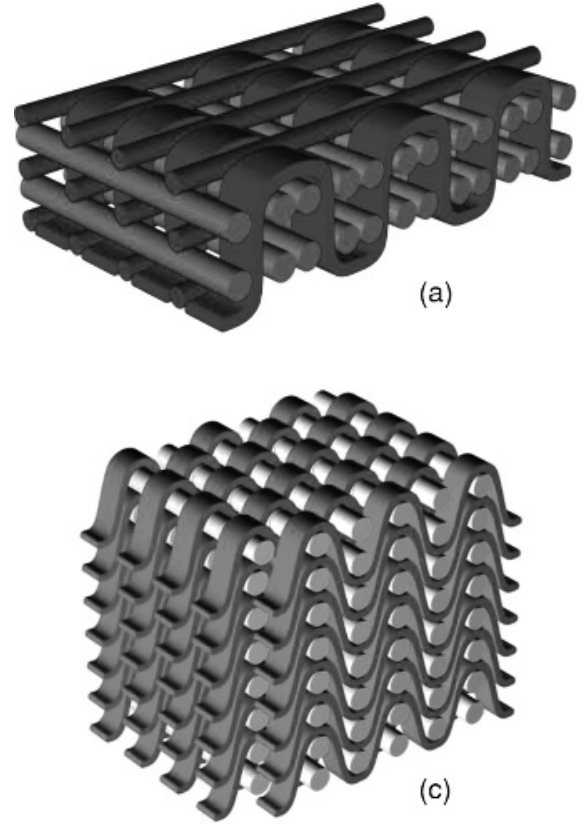
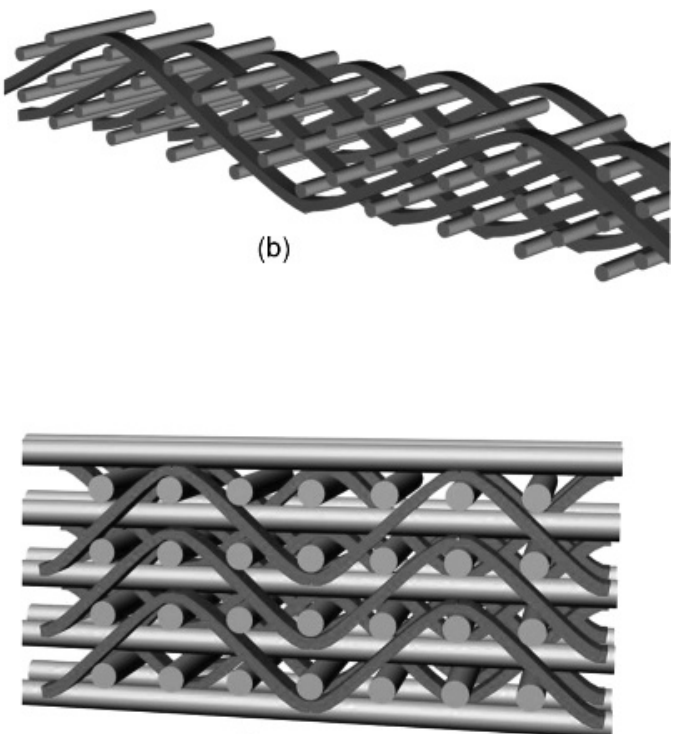

(d)

Figure 1.3 Different architectures of 3D woven composites: (a) 3D orthogonal woven composite, (b) 3D through-thickness angle interlock woven composite, (c) 3D layer to layer angle interlock woven composite, (d) 3D layer to layer angle interlock woven composite. 


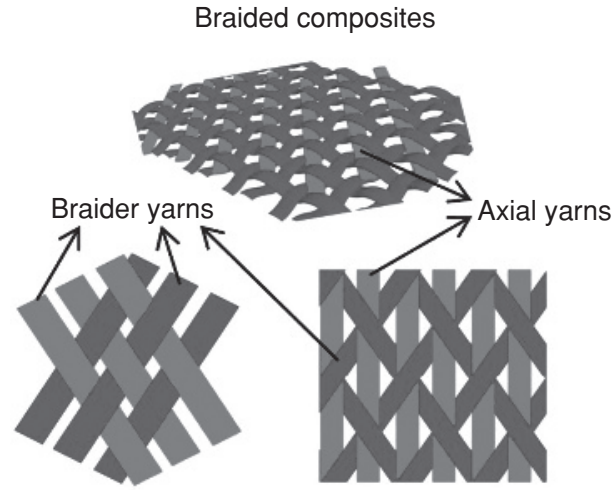

(a) (b)

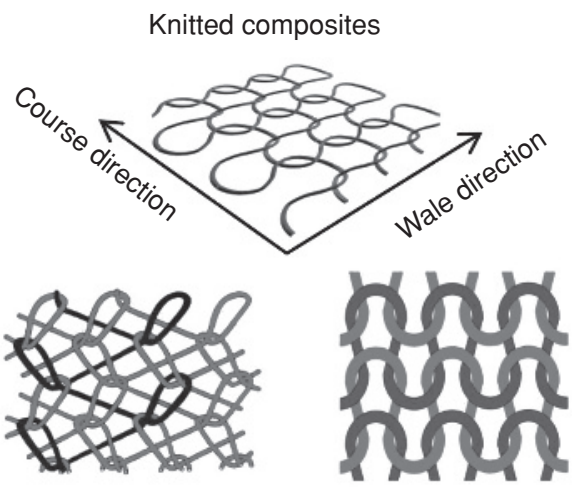

(c)

(d)

Figure 1.4 (a) 2D diamond braided composite, (b) 2D tri-axially braided composite, (c) warp knitted composite, (d) weft knitted composite.

composites is their high shear resistance. It is well noticed that weaver yarns in $2 \mathrm{D}$ woven composites, 3D angle interlock woven composites and 2D braided composites have a similar undulated shape; the description and modelling of this type of yarns will be discussed in the following section.

Knitted composites are textiles made from basic construction units called loops. They are divided into two types: warp knitted (Figure 1.4c) and weft knitted (Figure 1.4d) fabrics. They are characterised by the number of loops into horizontal direction, called course $(C=$ number of loops/unit length), and by the number of loops into vertical direction, called wale ( $W=$ number of loops/unit length).

\subsubsection{Hybrid Composites}

Hybrid composites are made from several layers of composites and other materials (Figure 1.1). In general, for automotive applications, it is well noticed that the aluminium -composite combination is used as a hybrid composite. The composite layer could be any kind of composites described previously. The composite layer is used to reinforce the aluminium structure in order to enhance its mechanical properties. It is remarked that the use of hybrid composites is increasing, especially in tubular structures subjected to impact loading.

\subsection{Application of Composite Materials in the Automotive Industry}

It is well remarked that the application of composites in the automotive industries is increasing. In which concern, the focus of this study is on new research concerning advanced composites. These new kinds of composites consist of polymeric or metallic matrices reinforced with long fibres of carbon, glass and Kevlar materials.

The application of advanced composites will be shown in the next sections by reviewing the recent works that have been done in order to enhance the understanding of composites during impact, fatigue load and other complex loads. The review of studies dealing with 


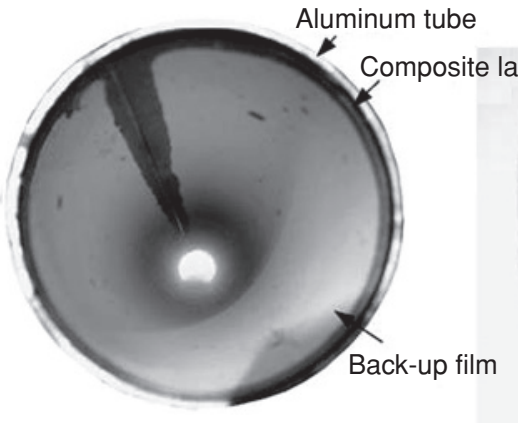

(a)

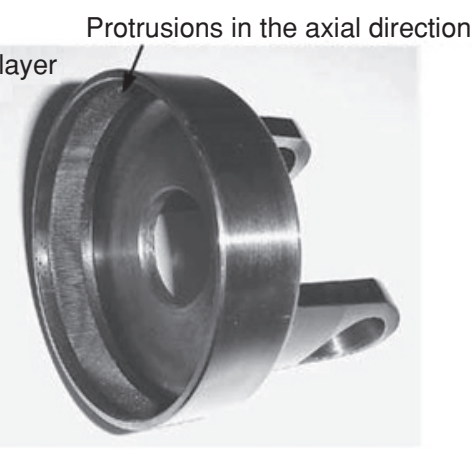

(b)

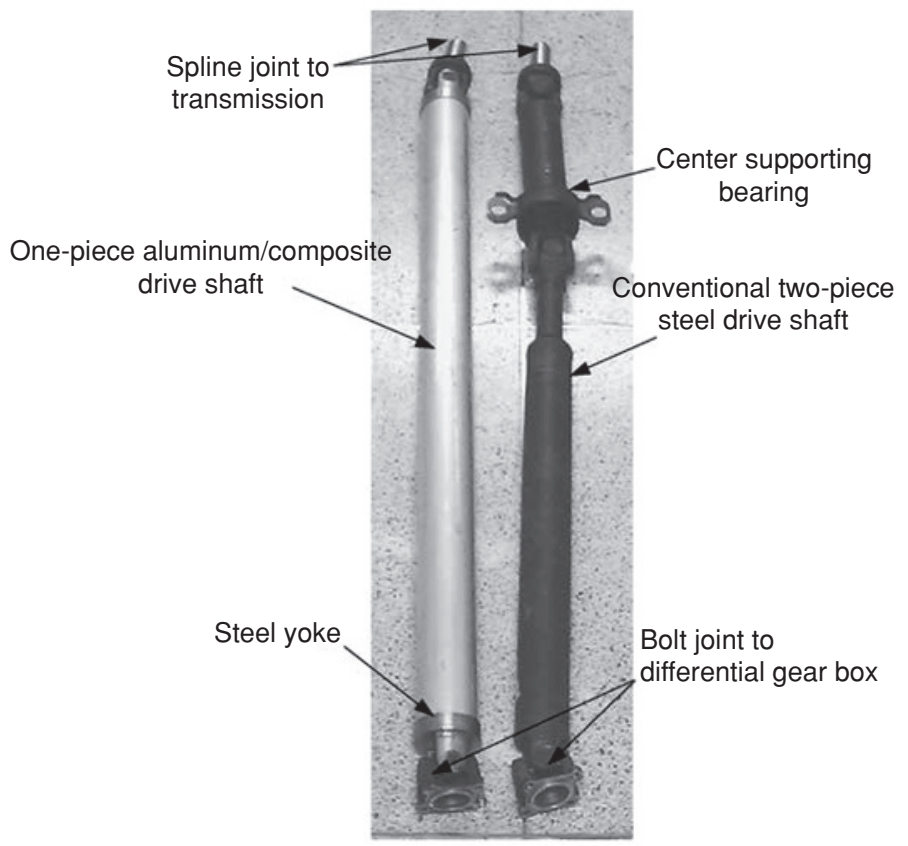

(c)

Figure 1.5 Hybrid composite driveshafts [35]. Reproduced from Ref. [35]. Copyright 2004 Elsevier.

advanced composites is divided into: crashworthiness studies, the development of automotive parts subjected to heavy static and dynamic loads, such as driveshafts (Figure 1.5), composite springs and gas turbines, and the use of natural fibre reinforced polymers as green composites replacing glass fibre reinforced polymer.

\subsubsection{Crashworthiness}

It is remarked that great attention is given to structural component material design related to car safety from impact and shock loading at different velocities. It is well known composites 
give the ability to design a lightweight structure that also can sustain much higher damage than steel and aluminium. The important parameter in crashworthiness studies of any structure to be investigated is the specific energy absorption (SEA; $\mathrm{KJ} / \mathrm{Kg}$ ) as well as the rate of work decay $(\mathrm{KJ} / \mathrm{s})$ to ensure a safe design that can protect the passengers [31].

Most studies are conducted to understand the behaviour of composite tubular parts. These structures are well used in the car chassis in order to enhance its crashworthiness during impact. Historically, the experimental work of Thornton and Edwards [32], in 1982, should be noticed. Different experimental tests subjected composite tubes made from glass, Kevlar and graphite fibres to impact loading. Later, other research was conducted as the work of Farley [33], in 1991, and Hamada [34], in 1996. Farley [33] studied the effects of crushing speed on the energy absorption capabilities of composite tubes. The investigated materials were graphite fibres/epoxy (Thronel 300/Fiberite 934) and Kevlar/epoxy (Kevlar fibres/Fiberite 934) composites. The main objective of that work was to determine the energy absorption capabilities as a function of crushing speed. However more recent work led by Hamada and Ramakrishna [34] concerning the optimisation of composite laminate fibre orientation for tubes subjected to impact loading was presented in 1996. The composite was a laminated carbon fibre reinforced poly-ether-ether-Kreton (PEEK) with $61 \%$ of fibre volume fraction. It was found that composite tubes with a fibre orientation of $\pm 15^{\circ}$ absorbed the most specific energy $(225 \mathrm{KJ} / \mathrm{Kg})$, and this was reported as the highest ever noticed in the literature for that time [34].

More advanced composites are used for energy absorption. Textile composites and especially carbon/epoxy braided composites are promising materials to be used, as shown by Chiu et al. [36]. In this study, the influence of braiding angle and axial yarn content was investigated. It was shown that the average width of the splaying fronds increased with increasing braiding angle, while it decreased with increasing axial yarn content. However, the highest specific energy absorption of $88 \mathrm{~kJ} / \mathrm{Kg}$ was noticed for $20^{\circ}$ of braiding angle. However, Bouchet et al. [37], in 2000, investigated the crushing behaviour of hybrid composite tubes. The composite was an UD carbon fibre (THR/300 from Hexcel)/epoxy polymer DGEBA with a fibre volume fraction of $34 \%$. The three layered carbon/epoxy UD composite was wrapped on an aluminium alloy tube with the direction of fibres perpendicular to the longitudinal axis of the tube. The influence of surface treatments on an aluminium alloy before bonding with a carbon/epoxy composite was investigated. It was shown that the surface treatments increased the specific energy absorption capacities of around 30\% between the chemically etched tube and the aluminium tube without surface treatment.

More recently, the advantage of composites over traditional materials as steel and aluminium in crush structures as tubes is well shown [38]. Quasi-static and intermediate rate axial crush tests were conducted on tubular specimens of carbon/epoxy (Toray T700/G83C) and glass/polypropylene (Twintex). The highest SEA measured $(86 \mathrm{~kJ} / \mathrm{kg}$ ) was observed for carbon/epoxy tubes at quasi-static rates with a $45^{\circ}$ chamfer initiator. Moreover, the highest energy absorption for Twintex tubes was observed to be $57.56 \mathrm{~kJ} / \mathrm{kg}$ during $45^{\circ}$ chamfer initiated tests at $0.25 \mathrm{~m} / \mathrm{s}$. However, with steel and aluminium, SEA values of 15 and $30 \mathrm{~kJ} / \mathrm{kg}$, respectively, were observed.

The study of crashworthiness has been also investigated with other types of automotive structural parts, such as bumpers or plates. In 2003, Corum et al. [39] studied experimentally the susceptibility of three candidate automotive structural composites subjected to low-energy impact damage. The reinforcements of composites that had the same urethane matrix consisted 
of random chopped-glass fibre and two stitch-bonded carbon-fibre mats, where one was in a cross-ply layup and the other in a quasi-isotropic layup. A pendulum device, representative of events such as tool drops, and a gas-gun projectile, representative of events such as kickups of roadway debris, were used to impact plate specimens. The glass-fibre composite was least vulnerable to damage, followed by the cross-ply carbon-fibre laminate, which had the same thickness. The quasi-isotropic carbon-fibre composite, which was thinner than the other two, sustained the most damage.

In addition, random chopped fibre reinforced composites were investigated by [40] as crash energy absorbers. According to [40], the Automotive Composite Consortium (ACC) is interested in investigating the potential use of these composites primarily because of the low costs involved in their manufacture, thus making them cost effective for automotive applications. The crashworthiness of composite plates subjected to quasi-static progressive crush tests was studied. The composite plates were made from three different kinds of materials: CCS100, HexMC and P4 composites. They were manufactured from Toray T700 chopped carbon fibre. The CCS100 composites were manufactured from chopped carbon fibre with YLA RS-35 epoxy resin using a compression moulding technique with a fibre volume fraction of $50 \%$ and a fibre length of $25.4 \mathrm{~mm}$ (1 inch). However, the random chopped carbon fibre epoxy resin HexMC composite plates, which had a fibre volume fraction of $57 \%$ and $50.8 \mathrm{~mm}$ ( 2 inch) fibre length, were compression moulded by Hexcel Composites LLC. The compression moulded P4 composite plates were manufactured from chopped carbon fibre having $50.8 \mathrm{~mm}$ ( 2 inch) fibre length and 36\% fibre volume fraction with Hetron epoxy resin. It is remarked that all three materials have shown superior SEA as desired by the ACC, which could lead to their direct application in the automotive industries.

\subsubsection{Composite Driveshaft and Spring}

Composites have been recently used as structural materials of driveshafts and also springs, due to their light weight and high resistance to fatigue. In this section, some recent developments and research in this domain is investigated.

Lee et al. [41] investigated the torsional fatigue characteristics of a hybrid shaft of aluminium -composite co-cure joined shafts with axial compressive preload. It was observed that the fatigue strength of the hybrid shaft was much improved by the axial compressive preload, exceeding that of a pure aluminium shaft. Also, the degradation of the fatigue resistance of the hybrid shaft at sub-zero operating temperature was overcome by the axial compressive preload.

A finite element study of a composite driveshaft was done by [42]. The material consisted of hybrid carbon/glass fibre reinforced epoxy laminated composite. The layers were stacked in the following configuration $\left[+45^{\circ}\right.$ glass $/-45^{\circ}$ glass $/ 0^{\circ}$ carbon $/ 90^{\circ}$ glass $]$ which consisted of one layer of carbon/epoxy and three layers of glass/epoxy UD composites. It was shown that, with a change of carbon fibre orientation angle from 0 to $90^{\circ}$, the loss in the natural frequency of the shaft was $44.5 \%$. Moreover, when shifting from the best to the worst stacking sequence, the drive shaft caused a loss of $46.07 \%$ in its buckling strength, which represented a major concern over shear strength in driveshaft design. In addition, the stacking sequence had an obvious effect on the fatigue resistance of the driveshaft.

More recently in 2011, Badie et al. [43] examined in their paper the effect of fibre orientation angles and stacking sequence on the torsional stiffness, natural frequency, buckling 
strength, fatigue life and failure modes of composite tubes. The studied composites consisted of carbon/epoxy and glass/epoxy laminates. The important remarks to be noticed form this study is that a carbon/epoxy driveshaft showed better torsional stiffens and fatigue life in comparison with a glass/epoxy driveshaft. Moreover, the stacking sequence with fibre orientation of $\pm 45^{\circ}$ showed a catastrophic sudden failure mode, while the stacking $90 / 0^{\circ}$ experienced progressive and gradual failure. For carbon/epoxy tubes a higher fracture strain was shown than that of glass/epoxy tubes. In addition, in hybrid tubes, the severe difference in torsional stiffness of the layers led to initially suppressed twisting. Also with these tubes, the severe difference in torsional stiffness of the layers led to containing matrix cracks at the outer plies, not extending towards the tube ends. Concerning the natural frequency, the bending natural frequency increased by decreasing the fibre orientation angle. Decreasing the angle increased the modulus in the axial direction.

Recently, the use of elliptical springs made from E-glass/epoxy composite was studied [44]. A finite element model was used to investigate them, based on spring rate, log life and shear stress parameters. As a conclusion of this study, composite elliptic springs can be used for light and heavy trucks with a substantial weight reduction. Moreover the optimisation study of geometrical parameters of the cross-sectional area of the spring shows that a ratio of $a / b=$ 2 yields the best mechanical properties.

\subsubsection{Other Applications}

The use of composites has also been observed with many other automotive parts, highpressure full composite cylindrical vessels [45], brake discs [46], automotive door skins [47], car bumpers [48] and automotive radiator heads made from a nylon -glass fibre composite [49]. In the automotive industry, some applications of MMC can be found, such as brake rotors, pistons, connecting rods and integrally cast MMC engine blocks. The application of carbon ceramic brakes in automotive domains (beside motors sports) was started 10 years ago with the Enzo Ferrari F60 [50]. However nowadays, due to their high cost, the application of these advanced brake discs is still limited to supercars (e.g. Corvette ZR1, Ferrari 458 Italia, Ferrari California, Nissan GTR, Audi R8, Lamborghini Gallardo, Lexus LFA) and motor racing cars [50].

More advanced composites are used in manufacturing a Japanese $100 \mathrm{~kW}$ gas turbine for automotive applications (Figure 1.6). In order to achieve some requirements such as higher thermal efficiency over $40 \%$ at a turbine inlet temperature of $1350{ }^{\circ} \mathrm{C}$, lower exhaust emissions to meet Japanese regulations and multi-fuel capabilities, the application of ceramic matrix composite was investigated by Kaya [51]. Parts made from different carbon fibre reinforced ceramic matrix showed higher mechanical properties, reliability against thermal shock, particle impact damage and creep resistance.

Other kinds of composites could also have a promising future in automotive applications as polymeric nanocomposites [52]. As reported; nanocomposites could afford a weight saving of about $80 \%$ in comparison with steel [52]. They could be produced by incorporating nanometresize clay particles in polymeric matrices such as polypropylene (PP), polyethylene (PE), polyesters, or epoxies. Different methods could be used to produce nanoncomposites, as one of these methods is the in situ intercalation polymerisation method, pioneered by the Toyota 


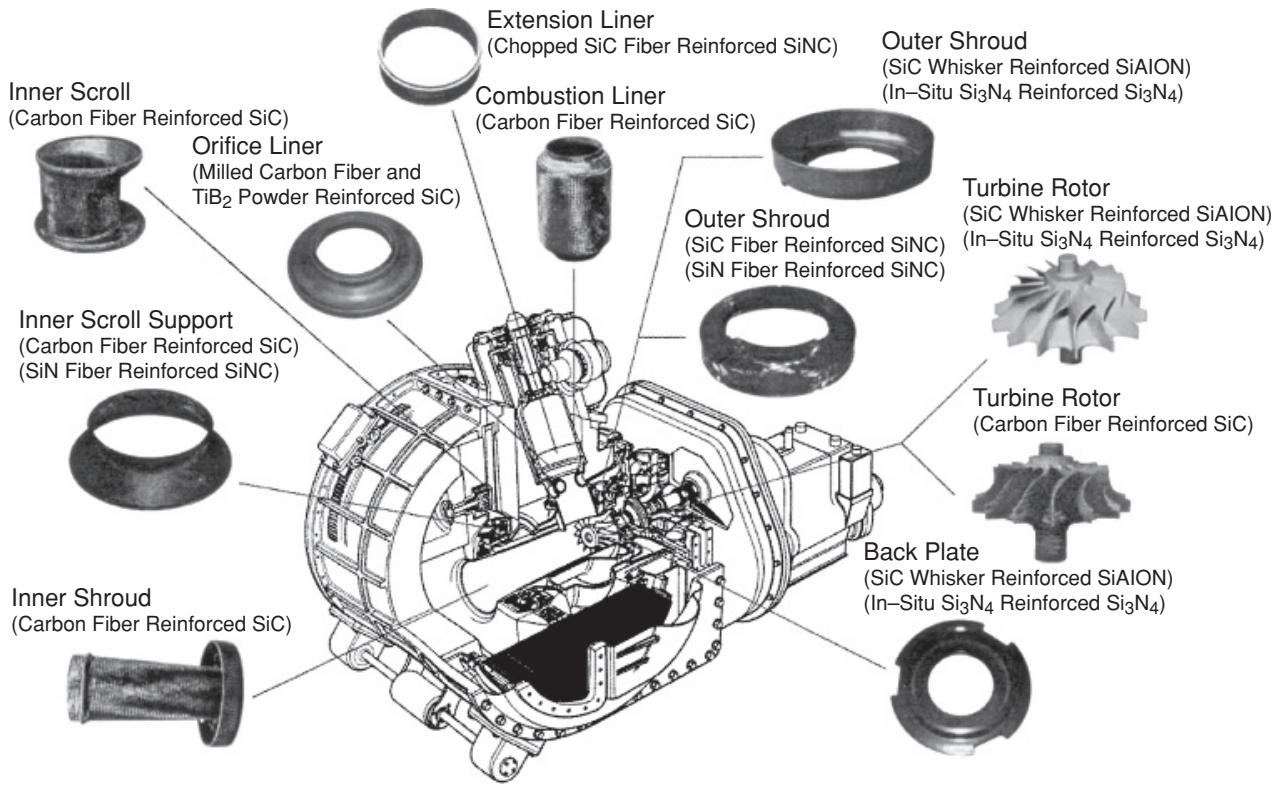

Figure 1.6 Carbon ceramic $100 \mathrm{Kw}$ gas turbine [51]. Reproduced from Ref. [51]. Copyright 1999 Elsevier.

Motor Company [53]. This method was used to create a nylon 6-clay hybrid (NCH), used to make a timing-belt cover, which could be considered as the first practical example of polymeric nanocomposites for automotive applications [54].

\subsection{Green Composites for Automotive Applications}

Due to the demanding needs for environmentally friendly composites, the automotive industry is seeking environmentally friendly biodegradable renewable composite materials and products. Over the last few years, a number of researchers have been involved in investigating the potential use of natural fibres as load bearing components in composite materials [55-58]. The use of such materials in composites has increased due to their relatively low cost, their ability to be recycled and their high strength to weight ratios.

Natural fibres show a potential as a replacement for inorganic fibres such as glass or aramid fibres in automotive components such as trim parts in dashboards, door panels, parcel shelves, seat cushions and cabin linings [59-61]. Mercedes-Benz used an epoxy matrix with the addition of jute in the door panels in its E-class vehicles [62].

Wambua et al. [63] studied the possibility of replacing glass fibres by natural fibres. They investigated the mechanical properties of sisal, hemp, coir, kenaf and jute reinforced polypropylene composites. The tensile strength and modulus increased with increasing fibre volume fraction. The mechanical properties of the natural fibre composites tested were found to compare favourably with the corresponding properties of glass mat polypropylene 
Advanced Composite Materials for Automotive Applications

Table 1.4 Mechanical properties of most used natural fibres compared to E-glass fibres $[68,69]$.

\begin{tabular}{lcccccc}
\hline Mechanical properties & E-glass & Flax & Hemp & Jute & Ramie & Sisal \\
\hline Density $\left(\mathrm{g} / \mathrm{cm}^{3}\right)$ & 2.55 & 1.4 & 1.48 & 1.46 & 1.5 & 1.33 \\
Young's modulus (Gpa) & 73 & $60-80$ & 70 & $10-30$ & 44 & 38 \\
Tensile strength (Mpa) & 2400 & $800-1500$ & $550-900$ & $400-800$ & 500 & $600-700$ \\
Elongation at failure (\%) & 3.0 & $1.2-1.6$ & 1.6 & 1.8 & 2.0 & $2.0-3.0$ \\
\hline
\end{tabular}

composites. The specific properties of the natural fibre composites were in some cases better than those of glass. This suggested that natural fibre composites have a potential to replace glass in many applications that do not require very high load bearing capabilities.

Davoodi et al. [64] investigated the hybridisation of natural fibres with glass fibres for improving the mechanical properties over the natural fibres alone. A hybrid kenaf/glass fibre composite was investigated for a car bumper beam as a structural automotive component. They found that some mechanical properties such as tensile strength, Young's modulus and flexural modulus of the hybrid composite were similar to those of a typical glass mat thermoplastic bumper beam. However, the impact strength was lower, which showed the potential for the utilisation of the hybrid natural fibres by optimising some structural design parameters.

Recently the use of natural fibres in automotive domains has expended. It is reported that the growth of bio-fibres in automotive components is expected to increase by 54\% per year [65]. Some kinds of strong, lightweight and low cost bio-fibres are introduced to replace glass fibre reinforced polymers in many interior applications. Fibres such as jute, kenaf, hemp, flax, banana, sisal and also wood fibre are making their way into the components of cars (Table 1.4). The bio-fibre reinforced polymers are used for door panels, seat backs, headliners, package trays, dashboards and trunk liners. Many review papers [60, 66, 67] have discussed the use of these fibres as reinforcement of a polymeric matrix, known as green composites. These papers reviewed the mechanical properties of fibres, matrices and composites. As well, they discussed the potential replacement of glass fibre reinforced polymer by the green composites, taking into account their ecological and economical influence.

Ashouri [61] presented in 2008 a review paper that discussed the use of wood plastic composite in the automotive industries. The main advantages shown by wood fibres compared to other kinds of natural fibres are to reinforce plastics due to their relative high strength and stiffness, low cost, low density, low $\mathrm{CO}_{2}$ emission, biodegradability and being annually renewable. In the same prospect, in 2010, Alves et al. [70] pointed out the advantages of applying other kinds of natural fibre composites, jute fibre composites, in buggy enclosures. The study aimed at presenting the ability to replace glass fibre composites by jute fibre composites, by showing that the use of natural fibres will improve the overall environmental performance of the vehicles.

More recently, an important review study of the green composites properties was done by Koronis et al. [60]. The potential use of these kinds of composites for automotive application was discussed. It was shown that bio-fibres, also known as natural fibres, could have good mechanical properties in comparison with glass fibres. Databases were presented for the important mechanical properties of some natural fibres, polymeric matrices, as well as their composites. 


\subsection{Modelling the Mechanical Behaviour of Composite Materials}

The modelling of the mechanical behaviour of composite materials has taken a major interest in recent years. Two main methods are used to determine the mechanical behaviour of composites: analytical models and numerical models (based on finite element analysis). Numerical models have taken most attention, due to the development in computation tools and software. It is noticed that these models are more trusted and widely used by industries. However, their implementation consumes a lot of time, beside the need to use super computers. In contrast, analytical models offer straightforward solutions and are more flexible and easier tools in terms of geometrical modelling and homogenisation methods. Moreover, they need less computation time without the necessity of super computers, and there is the ability of simple integration of analytical models in optimisation tools.

The modelling of the mechanical behaviour of composites must pass at first by the prediction of the stiffness matrix of the composite as a homogenised material. In contrast with metals, which have isotropic behaviour, composites with long fibres are treated as orthotropic materials. In addition, it should be noticed that some fibres, like carbon and graphite fibres, have anisotropic behaviour, in general considered transversely isotropic, while others, like glass fibres, are considered to have isotropic behaviour. Thus, the estimation of elastic properties and ultimate strengths presents a major challenge for researchers.

Analytical or numerical modelling of the mechanical behaviour of composites aids the optimisation of any structural component made of it. However, the variety of composites imposes a real challenge and intensive work in order to determine all the required mechanical properties. The detailed discussion of methods used to determine elastic properties, ultimate strengths, fatigue and impact behaviour, is considered to be out of the scope of this chapter. However a brief review of available analytical and numerical models used as homogenisation methods is presented.

\subsubsection{Modelling the Elastic Properties of Unidirectional Composites}

The prediction of the elastic properties of unidirectional composites using micro-mechanical models or FE methods is considered to be a basic stage in order to determine the mechanical properties of laminates or textile composites. The effective stiffness and compliance matrices of a transversely isotropic material are defined in the elastic regime by five independent engineering constants: longitudinal and transversal Young's moduli, longitudinal (also known as axial) and transversal shear moduli and major Poisson's ratio. Analytical models used to predict these engineering constants are known as micro-mechanical models. They can be categorised into four categories: phenomenological models, elasticity approach models, semi-empirical models and homogenisation models:

- Phenomenological models: rule of mixture (ROM); Reuss [71] model.

- Semi-empirical models: modified rule of mixture (MROM); Halpin-Tsai model [72]; Chamis model [73].

- Elasticity approach models: composite cylinder assemblage (CCA) model of Hashin and Rosen [74]; Christensen generalised self-consistent model [75].

- Homogenisation models: Mori-Tanaka (M-T) model [76]; self-consistent (S-C) model [77]; bridging model [78]. 


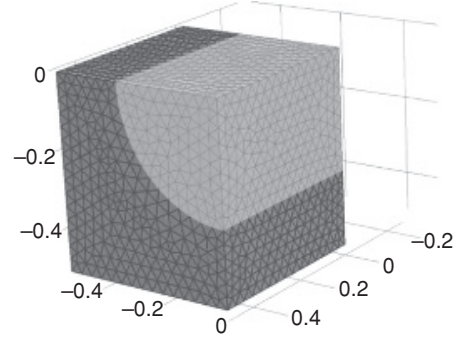

1/4 Square array

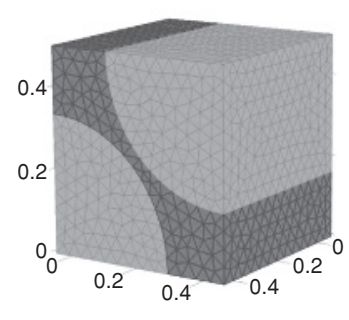

1/4 Diamond array

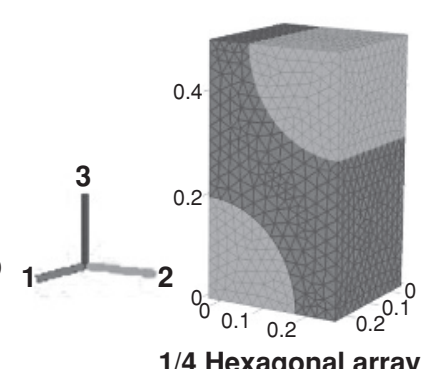

1/4 Hexagonal array

Figure 1.7 Meshing of square, diamond and hexagonal array unit cells.

Numerical FE modelling is widely used in predicting the mechanical properties of composites. Numerical modelling is a reliable tool, but the time consumed on the geometrical dimensions definition and the corresponding calculation time represent a major disadvantage against analytical models. Moreover there are many discussions and studies that deal with the appropriate boundary, symmetric and periodic conditions required to evaluate the elastic properties of UD composites. In this domain, a major work was done by Li [79]. It should be noticed that numerical FE modelling requires geometrical modelling or representation of the unit cell. For UD composites, there are three types of idealised fibre arrangements: square array, diamond array and hexagonal array (Figure 1.7).

\subsubsection{Modelling of Laminated and Textile Composites}

\subsubsection{Analytical Modelling}

Analytical models used for laminated and textile composites rely on two major factors for determining the stiffness of laminates and textiles: geometrical modelling and the homogenisation method. Geometrical modelling yields the required components for the homogenisation method, such as the volumes of the representative elementary volume (REV), layers, yarns and yarn sub-volumes. Furthermore, geometrical modelling gives the fibre volume fractions in the REV and in yarns as well as the orientations of yarns and yarn sub-volumes.

It should be noticed that the general scheme of homogenisation methods adopted for almost all analytical models are mainly based on a two-step homogenisation procedure: micro and macro levels. At micro level, the sub-volumes of subdivided REV are considered as unidirectional lamina with long fibres. Homogenisation at micro level is achieved, to predict the stiffness matrix of sub-volumes in a local coordinate system (123) where 1 is along the fibres. At this level, micro-mechanical models are employed.

At macro level, the transformation matrices are used to estimate the stiffness matrix of sub-volumes in a global coordinate system $(X Y Z)$ related to the REV. Then, a homogenisation method for the macro level is used.

For laminated composites, the famous classical lamination theory (CLT) method is the most reliable and used homogenisation method. However, for textiles, various homogenisation methods and approaches are used to assemble different sub-volumes, yarns and layers in order to predict the global stiffness matrix of the REV. These methods are based on: isostrain assumptions, iso-stress assumption, mixed iso-strain/iso-stress assumptions, or inclusion 
methods (Mori-Tanaka or self-consistent methods). A brief review of recent works concerning the modelling of elastic properties of textiles will be presented, while detailed review of these methods can be found in [80-84].

Historically, Ichikawa and Chou [84-88] were the first who tried to find analytical models in order to predict the elastic properties of $2 \mathrm{D}$ woven composites. They proposed three basic analytical models: the mosaic model [84], the fibre undulation model [84] and the bridging model [85]. Later, many models were proposed as extensions of these models [89-91].

Recently, most works have been conducted towards the modelling of textiles with complex geometries such as 3D $n$-directional braided composites and 3D woven.

The iso-strain model was used by Li et al. [92] for modelling the elastic behaviour of 3D five-directional braided composites. The predicted results showed good agreement with experimental results for axial Young's modulus and tensile strength with an error not exceeding 10\%. In addition, a 3D iso-strain model was presented by Shokrieh and Mazloomi [93]. The model was used to evaluate the stiffness of tri-axially braided composite. They compared their results to those experimental data presented by Quek et al. [94]. Results showed good predictions of the transverse Young's modulus $E_{y}$ and the in-plane shear modulus $G_{x y}$.

Concerning 3D woven composites, Yanjun et al. [95] and El-Hage et al. [96] used the iso-strain model to predict the effective elastic properties of $3 \mathrm{D}$ angle interlock woven ceramic composite and orthogonal and angle interlock woven composites. Also, mixed iso-strain/isostress models have been introduced in order to improve the prediction of elastic properties of such complex composites. Pochiraju and Chou [97,98] proposed a model for the prediction of anisotropic elastic stiffness of 3D textiles. The stiffness of the REV, decomposed into small subdivisions, is evaluated using an effective response comparison (ERC) technique. Concerning the angle interlock composites, the model yields good results in comparison to experimental data. Later, Tan et al. [99-102] developed two analytical models, the ZXY and $Z Y X$ models, to determine the mechanical properties and the thermal expansion coefficients of 3D orthogonal and angle interlock woven fabrics. The idealised REV is decomposed into sub-blocks which are assembled, under iso-strain and iso-stress conditions, using three models: the $X$ model, $Y$ model and $Z$ model along the $x, y$ and $z$ directions, respectively. The comparison with experimental results has shown that the models predict well the effective elastic properties of 3D orthogonal woven composites while less agreement is obtained in estimating the longitudinal Young's modulus $E_{x}$ of through-the-thickness 3D angle interlock woven composite [99]. However, Hallal et al. [103,104] proposed analytical models in order to enhance the prediction of $E_{x}$ of 3D angle interlock woven composite, especially for composites with a high content of undulated yarns. The models are also based on an assembling scheme of REV subdivisions in parallel, under the iso-strain condition, and in series, under the isostress condition. In [104], it is noticed that the iso-strain model have significant problems in predicting Young's modulus along a direction where the volume fraction, in the REV, of undulated yarns is high ( $x$ direction). However, the improved three-stage homogenisation method (3SHM) model has shown very good agreement with both experimental and numerical finite element (FE) results, especially for $E_{x}$.

\subsubsection{Numerical FE Modelling}

The prediction of the elastic properties and the stress -strain fields of laminated and textile composites have taken major interest with numerical FE modelling. The major problems 
remain in the time consumption and the meshing of complex geometries, as well as defining the contact between yarns and matrix.

A brief review of modelling composites with FE methods is presented. Cox et al. [105] and Xu et al. [106] developed a FE model, the binary model, to predict the mechanical properties of 3D interlock composites. Nie et al. [107] introduced the problem that represented the angle-interlock fabric in a more concise and efficient way, which is a major problem for the computer-aided design (CAD) of multi-layered angle-interlock woven fabric, as referred by Ko [108]. In the approach of Barbero et al. [109], a FE model of plain weave fabrics based on geometrical measurements from photographs was developed to determine the damage evolution using a meso-mechanical continuous damage formulation under tensile loading. Also a multi scale 3D mosaic model was applied for woven composites by Bogdanovich [110] where the stress and failure of 3D woven composites were studied. Moreover, Nehme et al. [111] used different meshing techniques, with tetrahedral mesh for the isotropic matrix and mapped hexaedral mesh for the transversely isotropic yarns, in order to achieve the FE discretisation.

\subsection{Discussion}

From the above sections, it is clearly shown from recent applications of composites in automotive industries that most attention is on using composites for crashworthiness applications in order to enhance car safety and to reduce the effect of impacts. In addition, there is an increasing consideration of a potential use of green composites in large masses by replacing glass fibre reinforced composites. Moreover, composites have been also used for other structural components, such as driveshaft, springs, brake discs, gas turbine and so on. However, the emergence of new types of composites has led to further development of new enhanced manufacturing processes for a large number of structures made from composites such as resin transfer moulding (RTM), performing and the liquid compression moulding manufacturing process.

Concerning the crashworthiness applications, the use of composites as the main structural component or as part of the hybrid material in tubular structures has taken the most consideration and most research. It is important to notice that these studies started more than 30 years ago. The important physical factors studied were the specific energy absorption and the work rate decay necessary to keep deceleration below a certain value during impact $(<20 \mathrm{~g})$. However, many parameters have been investigated in order to observe their effects on these factors, including the material kind, type of composite, stacking sequence of laminated composites and fibre orientation. Also, the review study reveals that for architecture, laminated composites are the most used; however, more recently braided composites started to receive more attention with their high shear strength. Moreover, glass fibres and carbon fibres are the most studied reinforcement with polymeric matrices. It is also clear the mechanical advantage that graphite and carbon fibres brought over glass fibre reinforced polymers and traditional materials. Concerning hybrids, the influence on the energy absorption of a surface treatment between the aluminium layer and carbon fibre reinforced polymer is studied. In addition, carbon short fibre reinforced polymers show great potential, with relatively low manufacturing cost and good mechanical properties concerning an impact crash.

Recent research also revealed that new directions in materials design tend to adopt composites as the first choice material for automotive structural parts that are subjected to severe 
static and dynamic loads. In these cases, the ultimate strength as well as the fatigue resistance of the material is crucial. One of these applications is the composite drive shaft. Finite element simulations have been conducted in order to find an optimised material that has high buckling strength, can resist the torsional fatigue loading and can increase the fundamental natural bending frequency. Hybridisation of studied driveshafts is done with carbon-epoxy UD/aluminium or carbon fibre-epoxy/glass fibre-epoxy laminates. All of the studied composites are made from long fibres, where the fibre orientation and the stacking sequence of laminate layers, as well as the material type (carbon fibre or glass fibre) are well investigated. It is well found these parameters have a good influence on the mechanical properties of driveshafts.

Moreover, other new applications of composites in automotive domains are shown, with E-glass/epoxy springs that could be used for heavy trucks and could save much weight, high performance gas turbine, advanced carbon ceramic brake discs and so on.

As recently observed, new natural fibres have emerged to substitute glass fibres for mostly interior automotive parts. Naturel fibre reinforced polymers are known as green composites due to their ecological and economic effects. Natural fibres such as woods, jute, Kenaf and flax have lower densities than most used glass fibres. It is found that these composites could have a promising future especially with automotive applications, while until now the dominant natural fibres are wood fibres. Much of the research observed recently just focused on some of the mechanical properties of these composites in comparison with glass fibre reinforced polymers, with more focus on their ecological and economical influences.

In general, it is remarked how composites gives many opportunities to offer solutions for many automotive applications. However, the large variety of fibres, matrices and architectures to form a composite material, led to much research work involving the optimisation and material design of automotive structures. In addition, it is noticed that unidirectional long-fibre laminated composites well dominate the research and world market concerning automotive applications. While some attention is found related with more advanced types of composites, such as braided composites and nanocomposites, there is almost an absence of 3D woven and knitted composites.

\subsection{Conclusion}

This chapter has presented an overview of recent applications of composites in automotive domains. The use of composites is investigated for saving weight and enhancing stiffness and strength against fatigue or crash, which leads to the design of safer vehicles. It is shown that the advantage of composites, especially by saving weight or the use of natural fibres has enormous ecological and economic effects.

It is found that most attention has been conducted to use composites for structural components to enhance crashworthiness. In addition, the use of composites will lead to saving much weight, when replacing traditional materials such as steel. Most of the composites used for tubular parts or plates consist of laminates. The influence of fibre types and laminate stacking sequence are the most investigated. However, the use of tri-axial braided composites as a more advanced composite has also been noticed in recent works. It is found that carbon and graphite fibres possess higher mechanical properties, while their manufacturing cost still presents a great disadvantage. 
Other automotive parts could benefit from composites, such as driveshafts, springs, gas turbine and brake discs. Composite laminates made from carbon fibre or glass fibre reinforced polymers are the most used for driveshafts and springs. From numerical finite element simulations, it is found that composites enhance the fatigue life as well as the stiffness of these components subjected to heavy dynamic load. For gas turbine and brake discs, advanced carbon ceramic composites have been used in order to sustain both thermal stresses and mechanical loads. Due to their high cost, the use of carbon ceramic brake discs is still limited to racing cars and modern supercars.

It is also significant to notice the attention green composites have taken recently. These composites, formed from natural fibre reinforced polymers, have been used to replace glass fibre reinforced polymers for many automotive parts. The ecological and economic benefits that green composites could afford lead to them being considered as a promising material.

\section{References}

[1] McWilliams, A. (2007) Advanced Materials, Lightweight Materials in Transportation, report, Report Code: AVM056A.

[2] Ghassemieh, E. (2011) Materials in Automotive Application, State of the Art and Prospects, New Trends and Developments in Automotive Industry, InTech, Marcello Chiaberge, ISBN: 978-953-307-999-8.

[3] Taub, A., Krajewski, P., Luo, A. and Owens, J. (2007) The Evolution of Technology for Materials Processing over the Last 50 Years: The Automotive Example. JOM, February.

[4] Auto News (2012) www.compositestoday.com, Posted on 9th October, 2012 in Automotive News (Accessed 8th February 2013).

[5] Auto News (2012) www.compositestoday.com, Posted on 15th June, 2012 in Automotive News (Accessed 8th February 2013).

[6] Brooks, R. (2000) Composites in Automotive Applications: Design, Comprehensive Composite Materials, Volume 6: Design and Applications, Springer, New York, pp. 341-363.

[7] Schouwenaars, R., Cerrud, S. and Ortiz, A. (2002) Mechanical analysis of fracture in an automotive radiator head produced from a nylon-glass fibre composite. Composites: Part A, 33, 551-558.

[8] Lee, S. and Lee, D. (2005) Composite hybrid valve lifter for automotive engines. Composite Structures, 71 , 26-33.

[9] Imihezri, S., Sapuan, S.M, Sulaiman, S. et al. (2006) Mould flow and component design analysis of polymeric based composite automotive clutch pedals. Journal of Materials Processing Technology, 171, 358-365.

[10] Beetz, C.P., Schmueser, D.W. and Hansen, W. (1989) Summary of panel discussion, "Challenges to the Researchers of Carbon Fibers and Composites from the Automotive and Boatbuilding Industries". Carbon, 27(5), 767-771.

[11] Chang, D.C. and Khetan, R.P. (1980) Advances in Material Technology in the Americas, Volume 1-Material Recovery and Utilization, ASME, New York, p. 51.

[12] Feraboli, P. and Masini, A. (2004) Development of carbon/epoxy structural components for a high performance vehicle. Composites: Part B, 35, 323-330.

[13] Feuillade, V., Bergeret, A., Quantin, J.-C. and Crespy, A. (2006) Characterisation of glass fibres used in automotive industry for SMC body panels. Composites: Part A, 37, 1536-1544.

[14] Ning, H., Pillay, S. and Vaidya, U. (2009) Design and development of thermoplastic composite roof door for mass transit bus. Materials and Design, 30, 983-991.

[15] Palanivelu, S., Paepegem, W.V., Degrieck, J. et al. (2011) Crushing and energy absorption performance of different geometrical shapes of small-scale glass/polyester composite tubes under quasi-static loading conditions. Composite Structures, 93, 992-1007.

[16] Zarei, H., Kroger, M. and Albertsen, H. (2008) An experimental and numerical crashworthiness investigation of thermoplastic composite crash boxes. Composite Structures, 85, 245-257.

[17] Pitarresi, G., Carruthers, J.J., Robinson, A.M. et al. (2007) A comparative evaluation of crashworthy composite sandwich structures. Composite Structures, 78, 34-44. 
[18] Guedes, R.M. (2007) Durability of polymer matrix composites: viscoelastic effect on static and fatigue loading. Composites Science and Technology, 67, 2574-2583.

[19] Hosseinzadeh, R., Shokrieh, M. and Lessard, L. (2006) Damage behavior of fiber reinforced composite plates subjected to drop weight impacts. Composites Science and Technology, 66, 61-68.

[20] Bartus, S.D. and Vaidya, U.K. (2005) Performance of long fiber reinforced thermoplastics subjected to transverse intermediate velocity blunt object impact. Composite Structures, 67, 263-277.

[21] Lanzi, L., Castelletti, L.M.L. and Anghileri, M. (2004) Multi-objective optimisation of composite absorber shape under crashworthiness requirements. Composite Structures, 65, 433-441.

[22] Mamalis, A.G, Manolakos, D.E., Ioannidis, M.B. and Papapostolou, D.P. (2004) Crashworthy characteristics of axially statically compressed thin-walled square CFRP composite tubes: experimental. Composite Structures, 63, 347-360.

[23] Lee, D.G., Lim, T.S. and Cheon, S.S. (2000) Impact energy absorption characteristics of composite structures. Composite Structures, 50, 381-390.

[24] Findik, F. and Tarim, N. (2003) Ballistic impact efficiency of polymer composites. Composite Structures, 61, 187-192.

[25] Davoodi, M.M., Sapuan, S.M. and Yunus, R. (2008) Conceptual design of a polymer composite automotive bumper energy absorber. Materials and Design, 29, 1447-1452.

[26] Bisagni, C., Di Pietro, G., Fraschini, L. and Terletti, D. (2005) Progressive crushing of fiber-reinforced composite structural components of a formula one racing car. Composite Structures, 68, 491-503.

[27] Launay, A., Marco, Y., Maitournam, M.H. et al. (2010) Cyclic behavior of short glass fiber reinforced polyamide for fatigue life prediction of automotive components. Procedia Engineering, 2, 901-910.

[28] Ruggles-Wrenn, M.B., Corum, J.M. and Battiste, R.L. (2003) Short-term static and cyclic behavior of two automotive carbon-fiber composites. Composites: Part A, 34, 731-741.

[29] Verpoest, I. (2009) Micromechanics of Continuous and Short Fibre Composites, Department of Metallurgy and Materials Engineering, Katholieke Universiteit Leuven, Belgium.

[30] Hexcel (2012) www.hexcel.com (Accessed 8th February 2013).

[31] Jacob, G., Fellers, J., Simunovic, S. and Starbuck, J. (2002) Energy absorption in polymer composites for automotive crashworthiness. Journal of Composite Materials, 36(7), 813-850.

[32] Thornton, P.H. and Edwards, P.J. (1982) Energy absorption in composite tubes. Journal of Composite Materials, 16(6), 521-545.

[33] Farley, G.L. (1991) The effects of crushing speed on the energy-absorption capability of composite tubes. Journal of Composite Materials, 25(10), 1314-1329.

[34] Hamada, H., Ramakrishna, S. and Sato, H. (1996) Effect of fiber orientation on the energy absorption capability of carbon fiber/PEEK composite tubes. Journal of Composite Materials, 30(8), 947-963.

[35] Lee, D.G., Kim, H.S., Kim, J.W. and Kim, J.K. (2004) Design and manufacture of an automotive hybrid aluminium/composite driveshaft. Composite Structures, 63, 87-99.

[36] Chiu, C.H., Tsai, K.H. and Huang, W.G. (1998) Effects of braiding parameters on energy absorption capability of triaxially braided composite tubes. Journal of Composite Materials, 32, 1964-1983.

[37] Bouchet, J., Jacquelin, E. and Hamelin, P. (2000) Static and dynamic behavior of combined composite aluminium tube for automotive applications. Composites Science and Technology, 60, 1891-1900.

[38] Brighton, A., Forrest, M., Starbuck, M. et al. (2009) Strain rate effects on the energy absorption of rapidly manufactured composite tubes. Journal of Composite Materials, 43(20), 2183-2200.

[39] Corum, J.M., Battiste, R.L. and Ruggles-Wrenn, M.B. (2003) Low-energy impact effects on candidate automotive structural composites. Composites Science and Technology, 63, 755-769.

[40] Jacob, G., Starbuck, J., Fellers, J. et al. (2006) Crashworthiness of various random chopped carbon fiber reinforced epoxy composite materials and their strain rate dependence. Journal of Applied Polymer Science, 101, 1477-1486.

[41] Lee, D.G., Kim, J.W. and Hwang, H.Y. (2004) Torsional fatigue characteristics of aluminium -composite co-cured shafts with axial compressive preload. Journal of Composite Materials, 38(9), 737-756.

[42] Abu Talib, A., Ali, A., Badie, M. et al. (2010) Developing a hybrid, carbon/glass fiber-reinforced epoxy composite automotive driveshaft. Materials and Design, 31, 514-521.

[43] Badie, M.A., Mahdi, E. and Hamouda, A.M.S. (2011) An investigation into hybrid carbon/glass fiber reinforced epoxy composite automotive driveshaft. Materials and Design, 32, 1485-1500.

[44] Abu Talib, A.R., Ali, A., Goudah, G. et al. (2010) Developing a composite based elliptic spring for automotive applications. Materials and Design, 31, 475-484. 
[45] Ruban, S., Heudier, L., Jamois, D. et al. (2012) Fire risk on high-pressure full composite cylinders for automotive applications. International Journal of Hydrogen Energy, 37, 17630-17638.

[46] Vasconcellos, M.A.Z., Hinrichs, R., da Cunha, J.B.M. and Soares, M.R.F (2010) Mossbauer spectroscopy characterization of automotive brake disc and polymer matrix composite (PMC) pad surfaces. Wear, 268, $715-720$.

[47] Puri, P., Compston, P. and Pantano, V. (2009) Life cycle assessment of australian automotive door skins. The International Journal of Life Cycle Assessment, 14, 420-428.

[48] Marzbanrad, J., Alijanpour, M. and Saeid Kiasat, S. (2009) Design and analysis of an automotive bumper beam in low-speed frontal crashes. Thin-Walled Structures, 47, 902-911.

[49] Schouwenaars, R., Cerrud, S. and Ortiz, S. (2002) Mechanical analysis of fracture in an automotive radiator head produced from a nylon-glass fibre composite. Composites: Part A, 33, 551-558.

[50] Brembo (2012) www.brembo.com (Accessed 8th February 2013).

[51] Kaya, H. (1999) The application of ceramic-matrix composites to the automotive ceramic gas turbine. Composites Science and Technology, 59, 861-872.

[52] Garcos, J.M., Moll, D.J., Bicerano, J. et al. (2000) Polymeric nanocomposites for automotive applications. Advanced Materials, 12(23), 1835-1839.

[53] Giannelis, E.P (1996) Polymer layered silicates nanocomposites. Advanced Materials, 8(1), 29-35.

[54] Kurauchi, T., Okada, A., Nomura, T. et al. (1991) Nylon 6-clay hybrid - synthesis, properties and application to automotive timing belt cover. SAE Technical Paper 910584.

[55] Du, Y., Yan, N. and Kortschot, M. (2012) Light-weight honeycomb core sandwich panels containing biofiberreinforced thermoset polymer composite skins: fabrication and evaluation. Composites: Part B, 43, 2875-2882.

[56] Akil, H.M., Omar, M.F., Mazuki, A.A.M. et al. (2011) Kenaf fiber reinforced composites: a review. Materials and Design, 32, 4107-4121.

[57] Summerscales, J., Dissanayake, N., Virk, A. and Hall, W. (2010) A review of bast fibres and their composites. Part 2 - Composites. Composites: Part A, 41, 1336-1344.

[58] Joshi, S.V., Drzal, L.T., Mohanty, A.K. and Arora, S. (2004) Are natural fiber composites environmentally superior to glass fiber reinforced composites? Composites: Part A, 35, 371-376.

[59] Jacob, M. and Thomas, S. (2008) Biofibers and biocomposites. Carbohydrate Polymers, 71, 343-364.

[60] Koronis, G., Silva, A. and Fontul, M. (2013) Green composites: a review of adequate materials for automotive applications. Composites: Part B, 44, 120-127.

[61] Ashori, A. (2008) Wood-plastic composites as promising green-composites for automotive industries! Bioresource Technology, 99, 4661-4667.

[62] Suddell, B. and Evans, W. (2005) Natural fibers, biopolymers, and biocomposites, in Natural Fiber Composites in Automotive Applications (eds A.K. Mohanty, M. Misra and T.L. Drzal), CRC Press.

[63] Wambua, P., Ivens, J. and Verpoest, I. (2003) Natural fbres: can they replace glass in fibre reinforced plastics? Composites Science and Technology, 63, 1259-1264.

[64] Davoodi, M., Sapuan, S.M., Ahmad, D. et al. (2010) Mechanical properties of hybrid kenaf/glass reinforced epoxy composite for passenger car bumper beam. Materials and Design, 31, 4927-4932.

[65] EU (2002) Annual Report of the Government-Industry Forum on Non-Food Uses of Crops, Department of Environment, Food and Rural Affairs Publications, EU, August.

[66] La Mantia, F.P. and Morreale, M. (2011) Green composites: a brief review. Composites: Part A, 42, 579-588.

[67] Zini, E. and Scandola, M. (2011) Green composites: an overview. Polymer Composites, 32(12), 1905-1915.

[68] Bismarck, A., Baltazar-Y-Jimenez, A. and Sarlkakis, K. (2006) Green composites as Panacea? Socio-economic aspects of green materials. Environment, Development and Sustainability, 8(3), 445-463.

[69] Gassan, J. and Bledzki, A.K., (2000) Possibilities to improve the properties of natural fiber reinforced plastics by fiber modification - jute polypropylene composites. Applied Composite Materials, 7(5-6), 373-385.

[70] Alves, C., Ferrao, P.M.C., Silva, A.J. et al. (2010) Ecodesign of automotive components making use of natural. Jute fiber composites. Journal of Cleaner Production, 18, 313-327.

[71] Reuss, A. (1929) Berechnung der Fliessgrense von Mischkristallen auf Grund der Plastizitätsbedingung für Einkristalle. Zeitschrift Angewandte Mathematik und Mechanik, 9, 49-58.

[72] Halpin, J.C. and Kardos, J.L. (1976) The Halpin-Tsai equations: a review. Polymer Engineering and Science, 16(5), 344-352.

[73] Chamis, C.C. (1989) Mechanics of composite materials: past, present, and future. Journal of Composite Technology and Research, 11, 3-14. 
[74] Hashin, Z. and Rosen, B.W. (1964) The elastic moduli of fiber reinforced materials. Journal of Applied Mechanics, 31, 223-232.

[75] Christensen, R.M. (1990) A critical evaluation for a class of micromechanics models. Journal of Mechanics and Physics of Solids, 38(3), 379-404.

[76] Mori, T. and Tanaka, K. (1973) Average stress in matrix and average elastic energy of materials with misfitting inclusions. Acta Metallurgica, 21, 571-574.

[77] Hill, R. (1965) Theory of mechanical properties of fibre-strengthen materials-III. Self-consistent model. Journal of Mechanics and Physics of Solids, 13, 189-198.

[78] Huang, Z.M. (2001) Micromechanical prediction of ultimate strength of transversely isotropic fibrous composites. International Journal of Solids and Structures, 38, 4147-4172.

[79] Li, S. (2008) Boundary conditions for unit cells from periodic microstructures and their implications. Composites Science and Technology, 68, 1962-1974.

[80] Tan, P., Tong, L. and Steven, G.P. (1997) Modelling for predicting the mechanical properties of textile composites - a review. Composites: Part A, 28, 903-922.

[81] Crookston, J.J., Long, A.C. and Jones, I.A. (2005) A summary review of mechanical properties prediction methods for textile reinforced polymer composites. Proceeding of IMechE, Part L: Journal of Materials: Design and Applications, 219, 91-109.

[82] Ansar, M., Xinwei, W. and Chouwei, Z. (2011) Modeling strategies of 3D woven composites: a review. Composite Structures, 93, 1947-1963.

[83] Hallal, A., Younes, R. and Fardoun, F. (2013) Review and comparative study of analytical modeling for the elastic properties of textile composites. Composites Part B: Engineering, Available online 8 February 2013, ISSN 1359-8368. doi: 10.1016/j.compositesb.2013.01.024

[84] Ishikawa, T. and Chou, T.W. (1982) Elastic behaviour of woven hybrid composites. Journal of Composite Materials, 16(1), 2-19.

[85] Ishikawa, T. and Chou, T.W. (1982) Stiffness and strength behaviour of woven fabric composites. Journal of Material Sciences, 17, 3211-3220.

[86] Ishikawa, T. and Chou, T.W. (1983) One-dimensional micromechanical analysis of woven fabric composites. AIAA Journal, 21(12), 1714-1721.

[87] Ishikawa, T. and Chou, T.W. (1983) In-plane thermal expansion and thermal bending coefficients of fabric composites. Journal of Composite Materials, 17(2), 92-104.

[88] Ishikawa, T. and Chou, T.W. (1983) Nonlinear behaviour of woven fabric composites. Journal of Composite Materials, 17(5), 399-413.

[89] Yang, J.M., Ma, C.L. and Chou, T.W. (1986) Fiber inclination model of three-dimensional textile structural composites. Journal of Composite Materials, 20(5), 472-484.

[90] Whitney, T.J. and Chou, T.W. (1989) Modeling of 3-D angle-interlock textile structural composites. Journal of Composite Materials, 23(9), 890-911.

[91] Byun, J.H., Whitney, T.J., Du, G.W. and Chou, T.W. (1991) Analytical characterization of two-step braided composites. Journal of Composite Materials, 25(12), 1599-1618.

[92] Li, D.S., Lu, Z.X., Chen, L. and Li, J.L. (2009) Microstructure and mechanical properties of three-dimensional five-directional braided composites. International Journal of Solids and Structures, 46, 3422-3432.

[93] Shokrieh, M. and Mazloomi, M. (2010) An analytical method for calculating stiffness of two-dimensional tri-axial braided composites. Composite Structures, 92, 2901-2905.

[94] Quek, S.C., Waas, A.M., Shahwan, K.W. and Agaram, V. (2003) Analysis of 2-D triaxial flat braided textile composites. International Journal of Mechanical Sciences, 45, 1077-96.

[95] Yanjun, C., Guiqiong, J., Bo, W. and Wei, L. (2006) Elastic behavior analysis of 3D angle-interlock woven ceramic composites. Acta Mechanica Solida Sinica, 19(2), 152-159.

[96] El-Hage, C., Younes, R., Aboura, Z. et al. (2009) Analytical and numerical modeling of mechanical properties of orthogonal 3D CFRP. Composites Science and Technology, 69, 111-116.

[97] Pochiraju, K. and Chou, T.W. (1999) Three-dimensionally woven and braided composites. I: a model for anisotropic stiffness prediction. Polymer Composites, 20(4), 565-580.

[98] Pochiraju, K. and Chou, T.W. (1999) Three-dimensionally woven and braided composites. II: an experimental characterization. Polymer Composites, 20(6), 737-747.

[99] Tan, P., Tong, L. and Steven, G.P. (1999) Micromechanics models for mechanical and thermomechanical properties of 3D through-the-thickness angle interlock woven composites. Composites: Part A, 30, 637-648. 
[100] Tan, P., Tong, L., Steven, G.P. and Ishikawa, T. (2000) Behavior of 3D orthogonal woven CFRP composites, part I. Experimental investigation. Composites: Part A, 31, 259-271.

[101] Tan, P., Tong, L. and Steven, G.P. (2000) Behavior of 3D orthogonal woven CFRP composites. part II, FEA and analytical modeling approaches. Composites: Part A, 31, 273-281.

[102] Tan, P., Tong, L. and Steven, G.P. (2001) Mechanical behavior for 3-d orthogonal woven E-Glass/epoxy composites. Journal of Reinforced Plastics and Composites, 20(4), 274-303.

[103] Hallal, A., Younes, R., Nehme, S. and Fardoun, F. (2011) A corrective function for the estimation of the longitudinal young's modulus in a developed analytical model for $2.5 \mathrm{D}$ woven composites. Journal of Composite Materials, 45(17), 1793-1804.

[104] Hallal, A., Younes, R. and Fardoun, F. (2012) Improved analytical model to predict the effective elastic properties of a 2.5D interlock woven fabric composite. Composite Structures, 94, 3009-3028.

[105] Cox, B.N., Carter, W.C. and Fleck, N.A. (1994) A binary model of textile composites-I. Formulation. Acta Metallurgica et Materialia, 42, 3463-3479.

[106] Xu, J., Cox, B.N., McGlockton, M.A. and Carter, W.C., (1995) A binary model of textile composites-II. The elastic regime. Acta Metallurgica et Materialia, 43, 3511-3524.

[107] Nie, J., Lu, S. and Gu, B., (2006) Fractional formula description of angle-interlock woven fabric construction. Journal of Industrial Textiles, 36(2), 125-132.

[108] Ko, F.K. (1999) 3D Textile Reinforced in Composite Materials, 3-D Textile Reinforcements in Composite Materials, Woodhead Publishing, CRC Press, England, pp. 9-40, ISBN 1855733765.

[109] Barbero, E.J., Trovillion, J., Mayugo, J.A. and Sikkil, K.K. (2006) Finite element modelling of plain weave fabrics from photomicrograph measurements. Composite Structure, 73, 41-52.

[110] Bogdanovich, A.E., (2006) Multi-scale modeling, stress and failure analyses of 3-D woven composites. Journal of Materials Science, 41, 6547-6590.

[111] Nehme, S., Hallal, A., Fardoun, F. et al. (2011) Numerical/analytical methods to evaluate the mechanical behavior of interlock composites. Journal of Composite Materials, 45(16), 1699-1716. 